\title{
Population growth and its impact on retirement age in the
}

\section{$\mathrm{UAE}$}

\author{
Waheeb Saeed Al Kamali \\ Hamdan Bin Mohammed Smart University \\ walkamali.ae@gmail.com,200112112@hbmsu.ac.ae \\ United Arab Emirates, Sharjah 301, UAE \\ United Arab Emirates, Dubai 71400, UAE
}

\begin{abstract}
The United Arab Emirates has the highest population growth rate in the Arabs region, with approximately 10 million people (Elessawy, 2017). It reported a five-year growth rate of $1.31 \%$ between 2015 and 2020 (Khan et al., 2019). The vast population growth has been attributed to an increase in birth rates. UAE government recently encouraged its citizens to give birth to reduce the disparity in population demographics between the expatriates and UAE citizens. Furthermore, a sharp increase in the influx of expatriates accounts for such an unprecedented population growth rate. The country has recently experienced an oil boom, which increased the country's availability of business opportunities, attracting expatriates to take such advantages.

The most significant concern for economists is how the revolution of technology combined with robust population growth will impact retirement age (Fisher \& Ryan, 2018). The current retirement age in UAE is 60 years, but some workers can retire at 65 after getting approval, according to the UAE labor laws (Alkhawaja \& Albaity, 2020). UAE is one of the leading technology hubs in the world. The country has significantly invested in technology and innovation. Ninety percent of people in the country are connected to the internet with personal computers at their homes (Coccia, 2018). As technological advancement takes center stage in the UAE, the availability of information will influence critical decisions from workers and the private sector at large.

What is the preference of the private sector in the UAE labor markets? Given a robust technological advancement coupled with a sharp influx of expatriates in the country, the private sector, and the public sector will have tough decisions to make before choosing either experienced retirees or young graduates (Sarvari et al., 2020). This research paper seeks to understand the dynamics in the UAE labor market and prospects resulting from high population growth rate, technological advancement, and the private sector's emergence. Through preliminary studies, the paper seeks insight into the causes of the high population growth rate, effects of technological advancements, and private sector business on the retirement age decisions among UAE inhabitants.
\end{abstract}

Key wordes: Population growth, human rescores, retirement age, UAE.

\section{Literature Review}

The review of preliminary studies on the topic seeks to understand the labor market dynamics in the UAE and the reasons for a recent surge in population within the country. The literature review will also guide an understanding of how technology impacts retirement age and other employment issues. The research materials used for the literature review are available through searches in the Educational Research Information Center in the U.S. Others were obtained primarily from the Virginia State Community Library both physically and through their website. 
Although some research materials highlighted under this section provide critical insight into labor dynamics and technological changes generally, the research will be modified to suit UAE as a country.

The review of literature under this study will be divided into different sections. Some sections will include the reasons for the population increase in the UAE, the relationship between technological advancement and employment patterns, and Private sector labor preferences in the UAE. The findings from this research will help guide the actual research that will be conducted from primary sources.

\subsection{Reasons for Population Increase in the UAE}

Koornneef, Robben, \& Blair (2017) investigated the reasons for a surge in population within the UAE. They conducted studies using UAE government websites and interviews with various high-profile leaders from the country and the entire Arabs region. They also searched for information from all public published sources and related databases. They conducted seventeen studies between 2001 and 2016 from the Arabs countries, and the data was recorded through notetaking, video recording, and tape recording. They synthesized data covering various responses regarding health sector financing and population growth financing strategies conducted by the UAE government.

According to Koornneef et al., 2017, the United Arab Emirates government had set up effective strategies to ensure robust population growth. Extensive healthcare reforms were pivotal to the UAE government for over ten years since 2001. The government had made huge investments towards financing primary health care and the construction of first-class hospitals in the country. Koornneef et al., Concluded that the extensive healthcare investment by the UAE government was a key influence on the increase in population within the country between 2001 and 2015. With an improved healthcare system, UAE citizens were guaranteed affordable infant medication access, giving birth in large numbers leading to a sharp rise in population within the country.

Daleure (2017) researched to examine the factors that led to sharp demographic variations in UAE. He examined published materials available in all online databases. From the research, the region's inhabitants were extensively engaged in traditional trading activities before the emergence and discovery of oil products in the country. They engaged in vast trade activities across the region with their other Arabs counterparts. The country was majorly made up of local citizens. Globalization was a rare aspect. After discovering oil products in the country, there was an oil boom, which made the country a global country. There was a high demand for labor from the external market to bridge the country's labor supply and demand (Daleure, 2017). Daleure concluded that the emergence of the oil boom resulted in an influx of expatriates in the country, making up the basis for the country's high population between 2001 and 2015.

\subsection{Relationship between Technology and Retirement Age}

Munnell, A. H. (2015) Around 1880, the percentage of the older male population at work began to decline sharply Experts attribute this decline to an unexpected and substantial stream of income from old-age pensions for Civil War veterans. The next big decline in the work rates of older men occurred after World War II, a response to the increasing availability of Social Security benefits and the expansion of employer pensions. The introduction of Medicare in 1965 and the sharp increase in Social Security benefits in 1972 probably led to the final leg of the decline in workforce activity of older men. And, because benefits were available at 62, Social Security may also explain part of the decline in workforce activity for men 55-64. The downward trajectory stopped around the mid-1980s and, since then, the labor force participation of men 55-64 and men 
65 and over has gradually increased. Many factors help explain this turnaround. )Munnell, A. H. 2015)

In a capitalist-driven world, the older section of human resources faces numerous challenges that make retirement life unbearable (Mahajan, 2020). Most of them choose to extend the retirement age to postpone the challenges they are likely to experience when they retire (Duquennois, 2020). Depression, isolation, and lack of information regarding social development are detrimental to happy living by the older generation.

Xie, Huang, \& Watkins (2012) researched the possible impact of technological advancement and information abundance on retirement decisions that the older section of human resource management makes. They conducted preliminary studies and interviewed workers aged between 40 and 55 from three different countries, namely, the U.S., U.K., and Qatar. They documented their findings and presented on tables the possible retirement decisions that most aging workers will take according to the growing wave of technological advancement and the emergence of technological hubs. Between September and November 2010, nine different databases were reviewed to avail data on possibilities of changes in retirement decisions due to technological changes. A total of twelve articles were presented for professional screening (Xie et al., 2012).

Forty percent of the interviewees claimed that they are likely to retire early with technological advancement. Many older workers are likely to lead happier lives at homes after retirement due to the availability of home computers and informational symmetry expedited by considerable investments in innovation and science in general (Fisher \& Ryan, 2018). Even though this literature review presents a smaller sample size, it provides an insight into the possible findings on retirement decisions.

Khedekar-Swaminathan \& Kulkarni (2018) found that older people experience numerous challenges after their retirement. They face depression due to lack of friends, experience information asymmetry, and encounter health problems due to aging disorders. Furthermore, Khedekar-Swaminathan \& Kulkarni (2018) reiterated that employees were happier at their jobs than when left to stay home. They were more likely to develop complexities related to old age diseases when staying at home. The introduction of modern technology with digitalized living lifestyles that connect most aging people to the internet is a crème de la crème strategy of averting social problems associated with early retirement (Ashour, 2020). More than 30 percent of aging workers would retire at the age of 50 if favorable conditions were guaranteed. They concluded that with expanding globalization, the emergence of an internet world, and growing investment in innovation in many countries, there will likely be a shorter working period with early retirement among many aging workers.

\subsection{Private Sector Labor Preferences in the UAE}

Toledo, H. (2013) Emiratization is a government policy designed to increase the participation of native workers in the production of goods and services in the UAE private sector. The policy has its origins in the 1990s out of government's concerns of private sector's heavy reliance on expatriate labor, high unemployment among native workers and the expectation of a relatively young Emirati population entering the labor force by the mid-2010s. It is estimated that in the next ten years, 200,000 young Emirati nationals (or 25 percent of the current Emirati population) will be entering the labor force. The Emiratization policy obliges certain industries, starting with the highly competitive banking sector, to achieve a minimum native/migrant ratio of 50 percent. The original deadline to meet this quota was 2007 but now has been extended. )Toledo, H. 2013).

Said (2019) conducted quantitative research to ascertain the labor market dynamics in the UAE and underlying factors leading to the country's success of economic diversification. The country has a market-friendly approach in its diversification goals leading to effective economic transformation (Yoo, Sawyerr, \& Alzahmi, 2018). The researcher developed an ARDL conintegrated method to ascertain the relationship between variables. Individual searches on various 
databases were also vital in this research. Corporates from the private sector also presented their views through a robust interview engagement. Both long run and short run assessment of the variables was conducted, and information was tabulated, including various aspects of privatesector labor dynamics (Said,2019).

Said found that the private sector is a crucial determinant of economic transformation in the UAE. Between 2016 and 2019, the private sector employed over 5.1 million people. This is over $50 \%$ of the entire population. The age characteristics showed that over $70 \%$ of people employed by the private sector belonged to the youthful category aged 24 years to 42 years. The private sector contributes immensely to the country's GDP; hence the government places excellent concern in supporting the sector.

The table below shows Said's findings regarding the country's employment patterns by the private sector for some years.

\begin{tabular}{ll}
\hline Year & Persons employed in millions \\
\hline $\mathbf{2 0 1 6}$ & 4.88 \\
$\mathbf{2 0 1 7}$ & 4.95 \\
$\mathbf{2 0 1 8}$ & 5.01 \\
$\mathbf{2 0 1 9}$ & 5.1 \\
\hline
\end{tabular}

Said concluded that the above pattern is likely to remain proportional in the future with increased employment opportunities from the private sector. Said added that UAE been a technological hub with considerable investments in the internet, science, and innovation, is likely to be filled by more youths with technological know-how. Many private companies will employ more youths to take advantage of their skills in transforming production activities. Many aging workers will be encouraged to retire since the private sector will be filled with a youthful population.

\section{Methodological Design}

\subsection{Introduction}

This study's primary purpose is to create an insight into a topic of concern for labor economics. The research seeks to establish the possible labor dynamics in the UAE labor market following technological advancement changes, changing population growth rates, with an expanding private sector that has an excellent preference for the youthful section of the human resource. The first objective will be attained through a review of materials relating to the country's changing population growth rates to give exact figures of population patterns. The research will further deeply analyze technological trends in the country to insight into innovation and science-related changes that are affecting the labor market. The articles reviewed under this section should provide an exact position of the country about global technological changes.

The general objectives of this research will be achieved through a literature review of previous studies, conducting primary research to obtain first-hand data, collection of data analysis of data to make it more useful to the scholarly generations and other stakeholders such as the investors and employees seeking to work in the UAE.

\subsection{Research Approach}

The primary data sources are intended to be used for this research. Having primary data though a survey questions by conducting a quantitative approach 115 participants, I had an understanding 
that using secondary data is more helpful for better result in understanding the outcome and get much insight to the research purpose.

\begin{tabular}{llll}
\hline & Quantitative Questions & $\begin{array}{c}\text { Percentage of } \\
\text { responders } \\
\text { YES }\end{array}$ & NO \\
\hline $\mathbf{1}$ & $\begin{array}{l}\text { Do you work in a government organization? } \\
\mathbf{2}\end{array} \quad \begin{array}{l}\text { Do you prefer early retirement? } \\
75 \%\end{array}$ & $\begin{array}{l}12.5 \% \\
25 \%\end{array}$ \\
$\mathbf{3} \quad \begin{array}{l}\text { Do you think that there is a correlation between retirement } \\
\text { age and unemployment rate? }\end{array}$ & $75 \%$ & $25 \%$ \\
$\mathbf{4} \quad \begin{array}{l}\text { Do you think that private sector consider employing early } \\
\text { experienced retirees? }\end{array}$ & $57.5 \%$ & $42.5 \%$ \\
$\mathbf{5} \quad \begin{array}{l}\text { Do you think HR management take into account the progress } \\
\text { of technology? }\end{array}$ & $55 \%$ & $45 \%$ \\
$\mathbf{6} \quad \begin{array}{l}\text { Do you think early retirement can help competitiveness of } \\
\text { the UAE in the world? }\end{array}$ & $85 \%$ & $15 \%$ \\
$\mathbf{7} \quad \begin{array}{l}\text { Do you think abundance of information for the last 25 years } \\
\text { effect retirement age? }\end{array}$ & $72.5 \%$ & $27.5 \%$ \\
$\mathbf{8} \quad \begin{array}{l}\text { Do you think it's better to retire after 20 years of working? } \\
\mathbf{9}\end{array}$ & $\begin{array}{l}\text { Do you think it is better to retire in the age of 40 help joining } \\
\text { privet sector? }\end{array}$ & $70 \%$ & $37.5 \%$ \\
$\mathbf{1 0}$ & $\begin{array}{l}\text { Do you prefer that retirement age is not combine with the } \\
\text { age of 50? }\end{array}$ & $80 \%$ & $20 \%$ \\
\hline
\end{tabular}

The understanding of the result through quantitative approach is that early retirement is preferable in term of the age and working years mostly in the government sector. Also the unemployment rate and competitiveness are effected by the retirement age from people perspective more over it confirmed the literature review outcome in this regards. HR management have many challenges in the technological era and the information management to better enhance their decision on retirement. With this said as insights I am not fully satisfied thus I will rely on secondary data.

Articles containing relevant information will be used to gather relevant data concerning this topic of study. This will be achieved by physically attending the community library to research and record data collected. Browsing the internet for online sources will also be helpful in this process.

\subsection{Data Sources}

The secondary data sources include journals, books, articles, and all publications regarding the labor dynamics, technological aspects, and retirement decisions among the aging people in UAE. All such secondary data will be found in all community and university libraries. Education Research and Information Center (ERIC) is also a vital source of data for this study. Online sources and publications that provide information on this topic will also be used effectively.

Different articles will be used as data sources to insight into the technological change effects in UAE. For example, by reviewing "A quantitative assessment of the private sector's role in economic diversification in UAE" by Said, an insight into the private sector preference regarding employment patterns is developed. The article gives a quantitative measure and analysis of employees' age characteristics in the country who serve in the private sector. Using the article, one can develop a comparative analysis project future patterns in the employment sector. 


\subsection{Data collection process}

Data will be collected from books, journals, articles, and all publications relevant to the study topic. The data collected will be recorded in Microsoft Excel spreadsheets for later analysis. All the relevant information will be recorded in notebooks and Microsoft word templates. The data will be later useful in the subsequent stages of the research.

Figures such as the number of people, ages, and other characteristics of the population serving under the private sector will be developed from a detailed survey of Said's article. The data relating to the number of people employed by the private sector and their characteristics will be recorded in Microsoft templates.

\subsection{Data Analysis}

After collecting and recording data, it will be analyzed to make it more useful for business decision-making. In this stage, data collected regarding population change will be tabulated and used to prepare comparative bar graphs to show the changes effectively. Microsoft Excel will also be used to develop trend analysis to show the expected age of retirement among many aging workers in the UAE following a population surge and technological know-how changes. A comparison table will be used to show the different preferences for early and late among UAE citizens.

\section{Expected Findings}

The expected Findings from the research are as follows.

3.1. Population Changes in UAE between 2016 and 2019

\begin{tabular}{|c|c|c|c|}
\hline Year & Population(millions & Growth rate & $\begin{array}{l}\text { Percentage of } \\
\text { expatriates }\end{array}$ \\
\hline 2016 & 9.4 & 1.32 & 11.4 \\
\hline 2017 & 9.6 & 1.16 & 11.8 \\
\hline 2018 & 9.7 & 1.45 & 17.3 \\
\hline 2019 & 9.9 & 1.31 & 20.2 \\
\hline
\end{tabular}

Retrieved from www.worldometers.info

The above data shows the comparison in the population of the country between 2016 and 2019 . The results show a positive population change annually. The continuous growth of population in the country over the past four years has resulted in a surge in the country's total number of inhabitants.

From the above research, it is evident that one of the factors leading to high population growth in the UAE is a sharp influx of expatriates. The country had over twenty percent of its population made up of expatriates in 2020. The hunt for opportunities emerging from the oil boom has attracted many investors and job seekers into the country leading to high population growth. (Kiviet \& Kripfganz, 2020).

It is also evident that an improvement in the healthcare system accounts for a high population growth rate in the country (Paulo, Loney, \& Lapão, 2019). The UAE government invested heavily in the healthcare sector between 2001 and 2015, creating assurance of improved healthcare services, which has led to a reduced death rate in the country. 
The increase in population within the country creates intense competition in the labor market. Currently, the private sector in the country is capable of employing approximately $50 \%$ of the population. The private sector has no full capacity to employ all the expatriates and locals hence creating a $9 \%$ unemployment rate in the country. If the current population growth rate continues, the future of employment depends heavily on the public sector's ability to absorb workers. Most aging expatriates will retire early to allow young graduates with high technological know-how.

\subsection{Retirement Age and effect on employment}

According to the UAE labor laws, the current retirement age in the UAE is 60 years (Alkhawaja \& Albaity, 2020). However, some workers may extend their retirement age to 65 upon approval by the labor laws. The extension of the retirement age has resulted in unemployment in the country. The private sector is not capable of absorbing a higher percentage of expatriates and locals. Most workers who extend their retirement age are from the public. The country is made up of the highest percentage of people aged between 25 years and 54yeras. Some of these people are expatriates seeking employment in the country. An extension of the retirement age renders many unemployed to the extent of a $9 \%$ unemployment rate.

\subsection{Technological Advancement in the country}

UAE is investing heavily in technology and innovation with anticipation of becoming a global innovation leader (Samsonova, 2021). Intensified machine learning, artificial intelligence, and an increase in the number of internet connections have been experienced in the country. The country intends to build some smart cities. With increased digital lifestyles, the lives of people in the UAE will change drastically.

Forty percent of people believe that such technological advancements will make life better for aging individuals and encourage them to offer tenure for an extended period. 30\% of expatriates believe that aging individuals will retire early with technological advancement since they will lack market-oriented skills in a digital era. Some investors believe the emergence of smart cities is a vital strategy that will help establish digital business platforms; hence there will be double employment opportunities (Ahmed \& Rafiuddin, 2018). Many aging workers will extend their retirement age since the market will still demand much of their services.

\subsection{Private Sector Preferences and Challenges}

\begin{tabular}{lcc}
\hline Year & $\begin{array}{l}\text { Number of people employed } \\
\text { (millions) }\end{array}$ & Age preferences \\
\hline $\mathbf{2 0 1 6}$ & 4.88 & $24-50$ \\
$\mathbf{2 0 1 7}$ & 4.95 & $25-54$ \\
$\mathbf{2 0 1 8}$ & 5.01 & $30-54$ \\
$\mathbf{2 0 1 9}$ & 5.1 & $29-52$ \\
\hline
\end{tabular}

Table showing public sector employment preferences in the UAE between four years. (www.worldometers.info)

According to the above information, the private sector in the UAE cannot employ more than 50 percent of the country's inhabitants. The investment and consumption are still low to cater for more employment in the country (Almarri, 2019). However, the private sector has shown an excellent preference for young individuals aged between 24 and 50 in its previous employment patterns. It is likely because of the high demand for an energetic class of young individuals in the 
market. The increased inclusion of science and technology in their universities creates a pool of skilled young professionals capable of solving market problems resiliently (Ahmed \& Rafiuddin, 2018). Most aging persons will be forced to retire early in the future because the market has a preference for young, energetic graduates. Past research shows that labor economists most prefer 55 years as the maximum retirement age.

\section{References}

Ahmed, G., \& Rafiuddin, A. (2018). Cultural Dimensions of Economic Development: A Case of UAE. Theoretical Economics Letters, 8(11), 2479-2496

Alkhawaja, S. O., \& Albaity, M. (2020). Retirement saving behavior: evidence from UAE. Journal of Islamic Marketing.

Almarri, K. (2019). Perceptions of the attractive factors for adopting public-private partnerships in the UAE. International Journal of Construction Management, 19(1), 57-64.

Ashour, S. (2020). Quality higher education is the foundation of a knowledge society: where does the UAE stand?. Quality in Higher Education, 26(2), 209-223.

Coccia, M. (2018). Theorem of not independence of any technological innovation. Journal of Economics Bibliography, $5(1), 29-35$.

Daleure, G. (2017). UAE Goes Global. In Emiratization in the UAE Labor Market (pp. 7-26). Springer, Singapore.

Duquennois, C. E. (2020). Essays in Development and Labor Economics (Doctoral dissertation, UC Berkeley).

Elessawy, F. (2017). The boom: Population and urban growth of Dubai City. Horizons Hum. Soc. Sci, 2, 26-41.

Fisher, G. G., \& Ryan, L. H. (2018). Overview of the health and retirement study and introduction to the special issue. Work, aging and retirement, 4(1), 1-9.

Khan, Z., Shahbaz, M., Ahmad, M., Rabbi, F., \& Siqun, Y. (2019). Total retail goods consumption, industry structure, urban population growth and pollution intensity: an application of panel data analysis for China. Environmental Science and Pollution Research, 26(31), 32224-32242.

Khedekar-Swaminathan, A., \& Kulkarni, S. (2018). Behavioral Challenges for Retirement Planning: A Study of Employees of the Information Technology Industry in Pune, Maharashtra. International Journal of Applied Behavioral Economics (IJABE), 7(2), 15-29.

Kiviet, J. F., \& Kripfganz, S. (2020). Reassessment of classic case studies in labor economics with new instrument-free methods. Mimeo. https://sites. Google. Com/site/homepagejfk.

Koornneef, E., Robben, P., \& Blair, I. (2017). Progress and outcomes of health systems reform in the United Arab Emirates: a systematic review. BMC health services research, 17(1), 1-13.

Mahajan, R. (2020). Design and Technology for Retirement Communities (Doctoral dissertation, University of Cincinnati).

Munnell, A. H. (2015). The average retirement age-an update. Notes, 1920, 1960-1980.

Paulo, M. S., Loney, T., \& Lapão, L. V. (2019). How do we strengthen the health workforce in a rapidly developing highincome country? A case study of Abu Dhabi's health system in the United Arab Emirates. Human resources for health, 17(1), 1-8.

Said, R. R. (2019). A quantitative assessment of the role of the private sector in economic diversification in UAE. Research in Applied Economics, 11(4), 23-35.

Samsonova, O. (2021). Educational technology in Abu Dhabi public schools: teaching with interactive whiteboards (IWBs). International Journal of Technology Enhanced Learning, 13(1), 60-77.

Sarvari, H., Chan, D. W., Banaitiene, N., Noor, N. M., \& Beer, M. (2020). Barriers to development of private sector investment in water and sewage industry. Built Environment Project and Asset Management.

Toledo, H. (2013). The political economy of emiratization in the UAE. Journal of Economic Studies.

Xie, B., Huang, M., \& Watkins, I. (2012). Technology and retirement life: A systematic review of the literature on older adults and social media. The Oxford Handbook of Retirement. Oxford University Press, New York.

Yoo, S. J., Sawyerr, O., \& Alzahmi, R. (2018). Examining the Effect of Cognitive Factors on Entrepreneurial Intention: The Case of the UAE. In ICSB World Conference Proceedings (pp. 1-7). International Council for Small Business (ICSB). 